\title{
The use of the Corner Sorting method in the NSGA-II in comparison with SPEA-II in the simultaneous optimization, the size, Shape and topology of two-dimensional trusses
}

\author{
Hamid Reza Loghmani ${ }^{1}$, Ali Ghoddosian ${ }^{2}$ \\ ${ }^{1}$ Department of Mechanical Engineering, Semnan Branch, Islamic Azad University, Semnan, Iran. \\ ${ }^{2}$ Department of Mechanical Engineering, University of Semnan, Semnan, Iran.
}

Article history:

Received July 2014

Accepted October 2014

Available online October 2014

\author{
hrloghmani@gmail.com \\ aghoddosian@semnan.ac.ir
}

\begin{abstract}
In this study, we are trying to do Non-dominated Sorting in simultaneous optimization at three levels the size, deformation and topology in two-dimensional trusses by using a new technique for Corner Sorting in genetic algorithms. Also, using this method and comparison with strong SPEA-II evolutionary algorithms in parameter, accuracy and extent of the Pareto curve occurs. Therefore, first we examine the algorithm in terms of numerical in the mathematics problems. And then, in ten-bars and three -bars trusses, we examine three levels of size, deformation and topology. The results show that the algorithm has very high accuracy to find solutions closer to the true Pareto optimal. Also, the algorithm has high capacity to find different topology at Pareto optimal level.

Keywords: multi-objective optimization, topology, Pareto curve, dominate, Non-dominated Sorting, Corner Sorting
\end{abstract}

\section{Introduction}

Optimization is to find one or more feasible solutions, which are related to the corresponding values for one or more of the objective function, the purpose of knowing these solutions in a problem is often design a solution to minimize the possible costs and maximize the possible or impossible capabilities, due to these major features, the solutions of the optimization are vary importance in practice, particularly in engineering design and scientific experiments and commercial decision. However, in recent decades, many researches have been done in this area to design effective and efficient optimization algorithms. Also, the use of these algorithms in optimization of structures has been of interest to many researchers. For example, the studies of the Samtani and Goldberg, in which the optimization in terms of size in terms of transient areas of members for design variables was considered, and the coordinates of the nodes and the connections between different users, is considered to be constant [35]. Coello and Christensen, modeling three goals (Weight, deflection, 
pressure), some routing optimization problem is solved in terms of size, as well as by using optimization tool, MOSES has been solved [1]. Imai and Schmit in the configuration optimization, in addition to members of the coordinates of the users, the node connections are variable [27]. Kaveh and Talatahari [15] and [18], in which the valuation operations based on a certain criteria, for example, this assessment criterion includes the total value or total cost of construction of a steel building system. However, most real-world search problems, including multi objective in nature, and if all goals are important, they were not used solely for a purpose, the different solutions may create different trade-offs between objectives, For example, these goals include making the minimum weight or maximum stiffness and maximum displacement or failure structure nodes diversion or the maximum natural frequency of free vibration or the maximum of elastic energy, and these goals expressed forced us to use the multi-objective optimization algorithm for this purpose. And explore Non-dominated solutions set in the objective space, this set provides information Non-dominated solutions with value about total design created in the engineering problem, and help us that we can make correct decision about this issue. The use of the multiple optimization algorithms has attracted many researchers on structural issues, for example Mathakari colleagues [23] use genetic algorithm to optimize truss structure. Liu and colleagues [22], use genetic algorithm for multi-objective optimization of the Tonsils design of structural operators in the steel moment frame. Paya and colleagues [28], the problem of structural frames design RC, is formulated as a multi-issue and in the optimization of solidify progressively, is optimized. In all these studies, some known multi-objective algorithm for the design problems of the structures optimization, have been used. And, then, the way which many researchers have used it to gain very good results by using multiple optimizations is arisen. For this purpose, Su and colleagues [32], using adaptive search strategy is integrated with NSGA-II, to solve the problem of optimization of truss. Omker and colleagues [27] using multivariate optimization in the PSO optimized hybrid structure design optimization problem, which is a multilevel problem. The main objective of this study was to compare the performance of the Corner Sorting on the NSGA-II method and its comparison with SPEA-II method in Simultaneous optimization of structural truss 3 bar and 10 bar, and also, we can see whether this method improves performance of Multi-objective algorithm including 1:The extent and 2:accuracy, and the aim of this study was to evaluate whether the use of this method improves the speed of convergence of the Pareto optimal solutions or not. At this stage, identifying other Multi-objective algorithms presented and reviewing them, their ability is examined. In recent decades, the literature on evolutionary computation of the general-purpose evolutionary algorithms has been proposed that they are based on different concepts, some of which include Pareto Evolutionary Algorithm SPEA-II[37] and sorting Multiobjective Evolutionary based on NSGA-II Analysis [6]. Of course, hybrid optimization algorithms also have attracted the attention of many researchers in recent years. For example, in references [11] and [31], gradient methods integrated with NSGA-II to increase the local search capability of this technique, and the convergence rate of this method increases. Hence, some of these algorithms require implementation over 100,000 times to prove capacity of the coverage area of the Pareto. In this study, the aim is to find whether this is able to solve problems with large number of variables, and find that whether algorithm can improve performance in the accuracy and extent parameters and is able to cover the full scope of Pareto area. Therefore, this algorithm with SPEA-II algorithm is studied in two groups, we initially examine this algorithm in unrestricted problems, and then reviewed it in the restricted problems, and then in the trusses with three bars, ten bars at three levels, it is examined. And it can be stated that the modified algorithm is compared with SPEA-II has the ability to cover the full Pareto curve with a very high degree of convergence.

\section{Initial actions}

To better understand the multi-objective optimization, the following concepts are important [4] and [7], which are summarized as follows: 
Definition 1: (overall multi-purpose optimization problem). In general, multi-functional optimization for optimization problem is defined as follows: the vector $x=(x 1, x 2, \ldots, x n)$, which the decision variables:

$\operatorname{Min}_{x \in \Omega} F(x)=f_{1}(x), f_{2}(x), \ldots, f_{m}(x)$
$q_{j}(x) \leq 0$
$h_{j}(x)=0 \quad j=1,2, \ldots, k$

Where, $\mathrm{q}$ is inequality constraints, and $\mathrm{h}$ is equals constraints in multi-objective optimization problem, where $\Omega$ is the set of decision vectors, and $m$ is the number of objectives.

Definition 2: (Pareto dominance) It is said that the vector $u=\left(u_{1}, u_{2}, \ldots, u_{n}\right)$ on the other vector $v=$ $\left(v_{1}, v_{2} \ldots, v_{n}\right)$ (which implies $u<v$ is dominant) if $u$ is somewhat less of $v$, namely, $\left\{\forall i \in\{1,2, \ldots, n\}, u_{i} \leq v_{i}\right.$ $\left.\wedge \exists i \in\{1,2, \ldots, n\}: u_{i}<v_{i}\right\}$

Definition 3: (Pareto optimal), it is said that the solution $x \varepsilon \Omega$, with respect to $\Omega$, is Pareto optimal, if only the $x^{\prime} \varepsilon \Omega$ where, there is not $v=\left\{f_{1}\left(x^{\prime}\right), f_{2}\left(x^{\prime}\right), \ldots, f_{n}\left(x^{\prime}\right)\right\}$ which on $u=\left\{f_{1}(x), f_{2}(x), \ldots, f_{n}(x)\right\}$ is dominant. The phrase "Pareto optimal" is considered that, according to total decision variable space is Significant, unless otherwise is specified.

Definition 4: (Pareto optimal set) for a given multi-objective optimization, $F(x)$, the Pareto optimal set is defined as $p=\left\{x \varepsilon \Omega \mid-\exists x^{\prime} \in \Omega F\left(x^{\prime}\right)<F(x)\right\}$ :

Definition 5: (Pareto optimal area) for a given multi-objective optimization, $F(x)$, the set of Pareto optimal, Pareto PF area is defined as: $\{P F=\{u=F(x) \mid x \in p\}$

\section{Background and Purpose}

At this part, it is better to divide my study into three parts, so that we can better explain the results and the manner of performance. For this purpose, first the Corner Sorting, and a brief description of the algorithm and the Not-dominated sorting algorithm stages based on Corner sorting, and then Hybrid optimizing in the three bars and ten bar trusses structure is presented.

\subsection{Corner Sorting Method}

In this method unlike previous methods in NSGA-II (non-dominated ranking), which is anew method, which is introduced by Wang [39], the number of required comparisons for dominated ratings can be reduced, and its speed is more than non-dominated sorting method. In the previous approach, a major challenge was the number of comparisons, because if the number of targets increases, the number of comparisons increases, and also can not be applied a savings in comparisons in multiobjective optimization problems effectively. However, corner or angle sorting is quick and simple method, which only needs $\mathrm{N}-1$ comparisons for $\mathrm{N}$ solution set, because compares as corner, it is called a corner sorting. That achieved by elimination of dominated solutions. In this method, the best values, the minimum value of the function in terms of each of objective functions is found (For minimization), and the dominated solution is defeated by the better value, and more, we put the best values in a empty set and we will delete them from the solution set. Now, again, these conditions for two better values which we do from the remaining solutions, and this is repeated until there is no solution. 

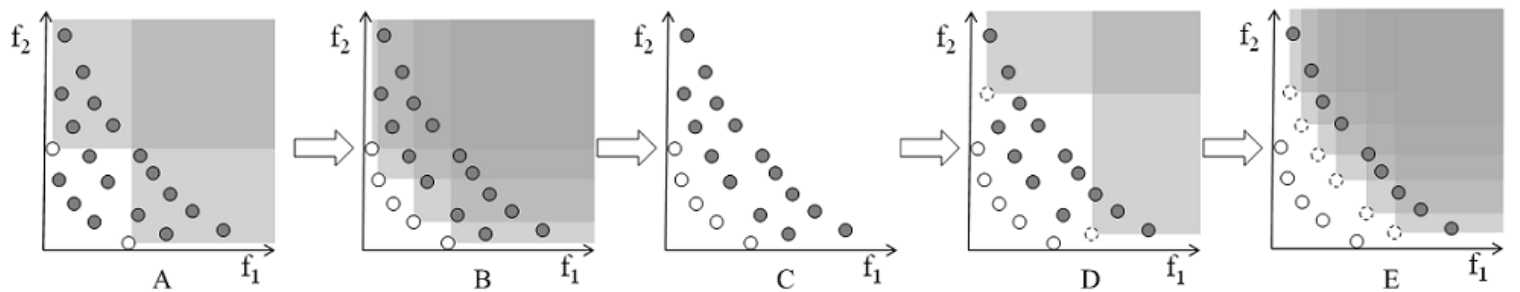

Figure 1- An example of executing Corner sorting A: Start sorting by two Optimal points than the two target functions: $\mathrm{B}$ Continue sorting by two Optimal points than the two target functions: $\mathrm{C}$ revealing the first rank: D Start sorting for Second rank: E determine second rank.

\subsubsection{The steps of the algorithm of the angle or corner method (Corner Sorting)}

1. Find best solution with respect to two objective functions (1.2).

2. Delete the dominated solutions than two good solutions (objective function has been found).

3. Put not-dominated solution in an empty set.

4. Back to 1, and again we find two good solutions to two objective functions (from the rest of the solutions from Step 2). Delete dominated solutions and put them in an empty set.

5. If all the solutions were dominated, what remains as rank is considered.

6. For the next ranks, and should not consider better not-dominated solution, and again in steps 1 to 5 , and the next ranks be created.

\subsection{Description Not-dominated Sorting algorithm Sort based on Corner Sorting}

Deb et al, proposed classification elitism or not-dominated sorting in the genetic algorithms, NSGA-II uses a plausible mechanism to provide of the density between the Pareto optimal solutions. In the first, population of children, $Q_{t}$ by using the parent population, $P_{t}$ is made. Here, instead of finding the not-dominated solutions of Qt, first two populations were combined with each other, and the population of $\mathrm{N} 2$ with size of the $2 \mathrm{~N}$ is created. Then, a not-dominated sorting to classify the entire population $R_{t}$ is used, of course, this sorting than sorting on Qt needs more comparisons. In this way, a general comparison between the members $R_{t}$, which is the sum of the number of children and parents is done, and after creating not-dominated different queues in order of priority (priority queues than each other), the next population one of the other queues, is filled. Filling $P_{t+1}$, with the not-dominated best queue is started, and then the second not-dominated queue, as well as the third and so on until the $P(t+1)$ to be filled, continues. Since the size of $R_{t}$ is equal to $2 N$, all its members may not be on $P(t+1)$ and remaining solutions of will be removed easily. Figure $(2)$ shows the performance of the algorithm. About solutions, which are removed in the last queue by using elitism operator, should be used more skills and solutions that are in less crowded area, must be protected.

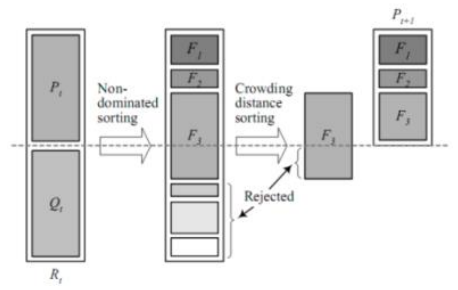

Figure 2- Demonstration of the performance of NSGA-II 


\subsubsection{The process of Not-dominated sorting algorithms based on Corner Sorting}

Step 1: Combine the population of children and parents and build our $\mathrm{R}_{\mathrm{t}}$ :

Classify $R_{t}$ by using Corner Sorting to $F_{i}$ queues, where $i=1,2, \ldots$, etc

$\mathrm{R}_{\mathrm{t}}=\mathrm{Q}_{\mathrm{t}} \cup \mathrm{P}_{\mathrm{t}}$

Step 2: Put $P_{t+1}=\phi, i=1$, then as long as $\left|P_{t+1}\right|+\left|F_{i}\right|<N$, we repeat the following operations:

$\left\{\mathrm{P}_{\mathrm{t}+1}=\mathrm{P}_{\mathrm{t}+1} \cup \mathrm{F}_{\mathrm{i}}, \mathrm{i}=\mathrm{i}+1\right\}$

Step 3: Run the process of swarm sorting $\mathrm{F}_{\mathrm{i}}<_{\mathrm{c}}$ and by using the concept of crowding distance, determine different values for $\left(\mathrm{N}-\left|\mathrm{P}_{\mathrm{t}+1}\right|\right)$ from Fi solutions.

Step 4: Create the population of children in $\mathrm{Q}_{\mathrm{t}+1}$ of $\mathrm{P}_{\mathrm{t}+1}$ by crowding tournament algorithm combination and mutation operators.

\subsubsection{Allocation procedures of the crossing distance}

Step 1: Set $L=|F|$ and $L=$ length of the queue $F$ for each $i$ solution from the set $F$, put $d_{i}=0$

Step 2: For each objective function $m=1,2, \ldots, M$, sort the $f_{m}$ set in descending and according to their value as well. Create the sorted index vector $\mathrm{I}^{\mathrm{m}}$, where $\mathrm{I}^{\mathrm{m}}=\operatorname{sort}\left(\mathrm{f}_{\mathrm{m}},>\right)$

Step 3: Dedicate from $m=1$ to $m=M$ a large number for solutions or $d_{I_{1}^{m}}=d_{I_{2}^{m}}^{m}=\infty$ and for other solutions, put:

$\mathrm{d}_{\mathrm{I}_{\mathrm{j}}^{\mathrm{m}}}=\mathrm{d}_{\mathrm{I}_{\mathrm{j}}^{\mathrm{m}}}+\frac{\mathrm{f}_{\mathrm{m}}^{\left(\mathrm{I}_{\mathrm{m}+1}^{\mathrm{m}}\right)}-\mathrm{f}_{\mathrm{m}}^{\left(\mathrm{I}_{\mathrm{j}-1}^{\mathrm{m}}\right)}}{\mathrm{f}_{\mathrm{m}}^{\max }-\mathrm{f}_{\mathrm{m}}^{\min }}$

$I_{j}$ index represents the $j$-th member of the list sorted in a second step. Thus, for all objective functions $I_{1}$ to $I_{m}$, the minimum and maximum values are attributed.

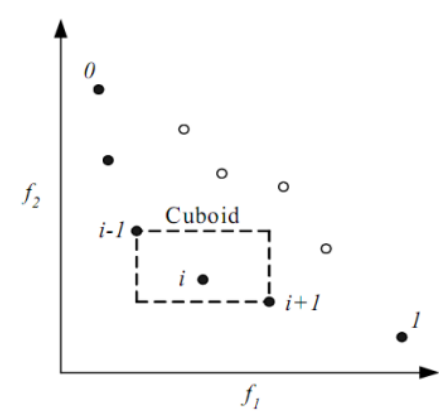

Figure 4- Calculation of the crowding distance

\subsection{Hybrid optimization}

In designing truss structures, some nodes tolerate overloaded or they are called backup nodes, and other nodes with the goal of better load distribution are used. Nodes must be presented on the justified truss (acceptable or feasible truss), and they are called basis nodes. The remaining nodes, ( $\mathrm{n}$ " nodes of them) are optional, and are called non-basic. The purpose of a truss design is finding the needed optional nodes in a truss, so that, in determining them often weight of the truss and its fail is considered. The method presented here, considers a ground structure, or a complete truss with all connections between nodes (basic or non-basic) in the building. Thus, a solution in the population of $\mathrm{GA}$, by the vector of $\mathrm{m}$ real number in the range $[-A, A]$ is displayed. Being member in the underground structure or not by comparing the transition zone of the members is specified by the 
user $\varepsilon$, is determined. If an area is smaller than $\varepsilon$, it is not necessary that it be in a truss. With the above discussion, we model the following non-linear problem (NLP) for truss areas of building:

Minimize $\quad F_{1}(A, \varepsilon)=\sum_{j=1}^{m} \rho_{j} L_{j} A_{j}$

Minimize $F_{2}(A, \varepsilon)=\max _{\mathrm{k}=1}^{\mathrm{n}} \delta_{\mathrm{k}}(\mathrm{A}, \varepsilon)$

$\mathrm{G}_{1} \equiv$ Truss is acceptable to user

$\mathrm{G}_{2} \equiv$ Truss is kinematic ally stable

$\mathrm{G}_{3} \equiv S_{j}-S_{j}(\mathrm{~A}, \varepsilon) \geq 0 \quad \mathrm{j}=1,2, \ldots, \mathrm{m}$

$\mathrm{G}_{4} \equiv \delta_{k}{ }^{\max }-\mathrm{s}_{\mathrm{k}}(\mathrm{A}, \varepsilon) \geq 0 \quad \mathrm{k}=1,2, \ldots, \mathrm{n}$

$G_{5} \equiv A_{i}^{\min } \leq A_{i} \leq A_{i}^{\max } \quad i=1,2, \ldots \ldots, m$

In the above non-linear problem, the design variables, the regions of the transition from the available members in the truss (shown by A) and the coordinates of all n' non-basic nodes are displayed by $\varepsilon$.

The first objective function shows the overall weight of the truss, and the second function states, the maximum deviation at any node.

The first constraint ensures that all basis nodes can be present in the truss, and second constraint is presented to ensure that existing connection in the GA solution shows a building, not a mechanism.

The third constraint, does not allow exceed the specified limits by the truss members, and the fourth constraint limits deviation in each of the nodes. Here, we have not used the G4.

In fact, we have used a limited method to find pressure at each member and deviation at each node foe any solution GA. Parameters $\delta_{j}$ and $\delta_{k}{ }^{m a x}$, are allowed strength of the $i$-th member and allowed deviation of the k-th node.

Now, we show how to implement the optimization of the truss in the flowchart below. 


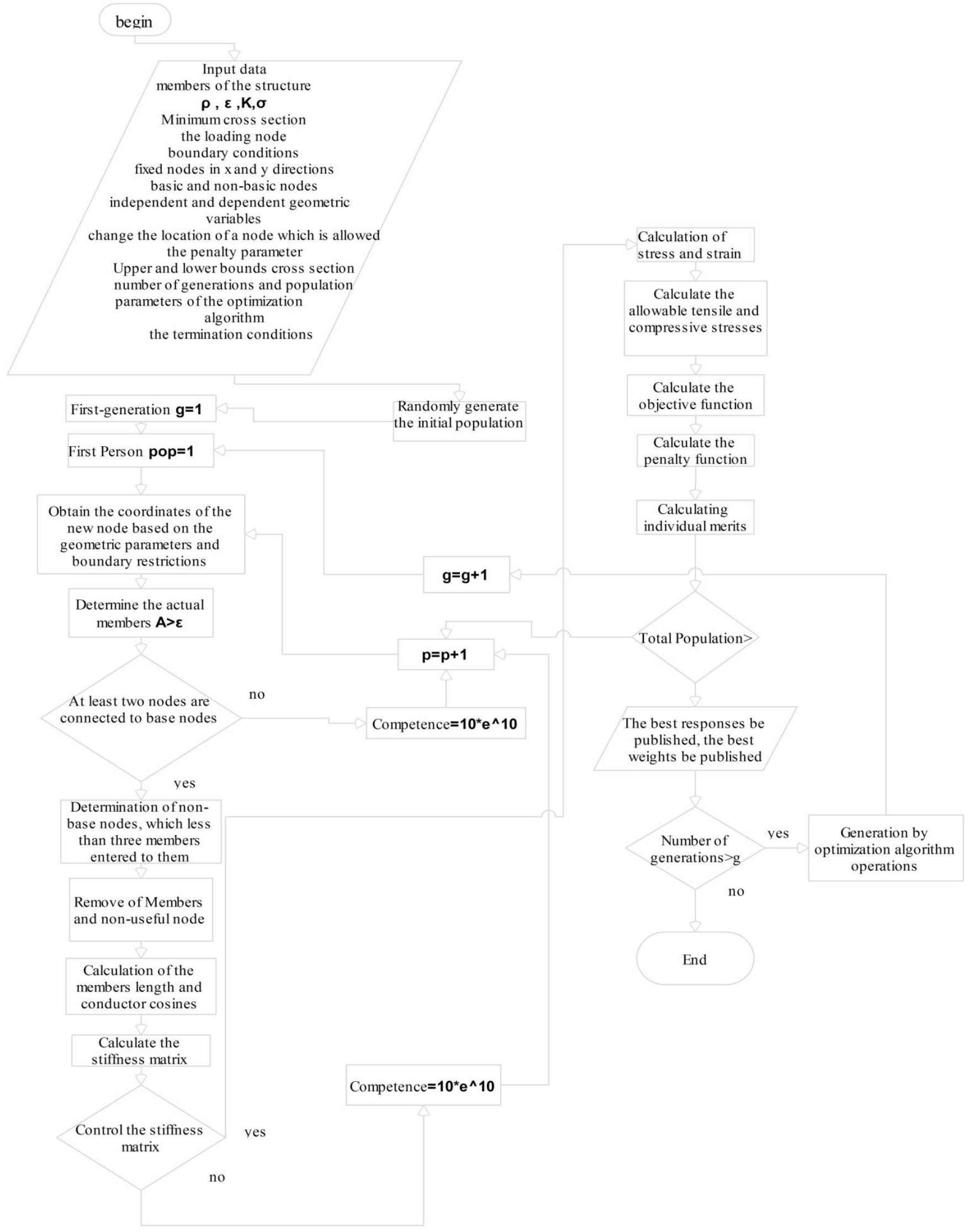

Figure 5- Truss optimization flowchart with optimization algorithms 


\section{Comparative Indicators of multi-objective algorithms}

To evaluate the performance of multi-objective algorithms, there are two main metrics categories:

1- Criteria for assessing the proximity to the Pareto optimal solutions, 2- the criteria to measure the density of the Pareto optimal solutions (Not-dominated) [38].

\section{4. Highest extension criterion}

This criterion, which was proposed by Zitzler, measures the length of the diameter of the Space Cube, which by the objectives final values for the set of not-dominated solutions is used. Equation (6) shows the computational procedure of this indicator.

$\mathrm{D}=\sqrt{\sum_{\mathrm{m}=1}^{\mathrm{M}}\left(\max _{\mathrm{i}=1}^{|\mathrm{Q}|} \mathrm{f}_{\mathrm{m}}^{\mathrm{i}}-\max _{\mathrm{i}=1}^{|\mathrm{Q}|} \mathrm{f}_{\mathrm{m}}^{\mathrm{i}}\right)}$

\subsection{Spacing Criterion}

This criterion, which was introduced by Scott, calculates the relative distance between consecutive solutions using equation (2). Where, $\mathrm{d}_{\mathrm{i}}=\min _{\mathrm{k} \in \mathrm{Q} \wedge \mathrm{K} \neq \mathrm{i}} \sum_{\mathrm{m}=1}^{\mathrm{M}}\left|\mathrm{f}_{\mathrm{m}}^{\mathrm{i}}-\mathrm{f}_{\mathrm{m}}^{\mathrm{k}}\right|$ and $\overline{\mathrm{d}}=\sum_{\mathrm{i}=1}^{|\mathrm{Q}|} \mathrm{d}_{\mathrm{i}} /|\mathrm{Q}|$. The distance measured is equal to the minimum valueof the sum of the absolute value of the difference in the values of the objective functions between the i-th solution solutions in the final Not-dominated set [3].

$\mathrm{S}=\sqrt{\frac{1}{|\mathrm{Q}|} \sum_{\mathrm{i}=1}^{|\mathrm{Q}|}\left(\mathrm{d}_{\mathrm{i}}-\overline{\mathrm{d}}\right)^{2}}$

\section{3. A criterion of the number of the Pareto solutions}

The value of the criterion of NOS indicates the number of Pareto optimal solutions, which can be found in each algorithm.

\subsection{Mean distance from the ideal solution}

This criterion, in order to calculate the average distance of Pareto solutions from the origin of coordinates is used. In the following equation, it is clear that whatever the criteria is less, the efficiency of the algorithm will be greater.

NID $=\frac{1}{\text { NOS }} \sum_{i=1}^{n} c_{i}$, where,$c_{i}=\sqrt{\sum_{i=1}^{m} f_{i j}^{2}}$

However, in multi-objective discussions based on Pareto approach, one of the goals was that, even Pareto front is closer to the center coordinates, so this criterion calculates the Pareto front distance from the best value of the population.

5. Set the parameters of the crossing and mutation in genetic algorithm NSGA -II in the SPEA-II multi-objective optimization

For selecting parents, we have used parent's binary tournament selection method between parents to create parents and here the single-point crossover ,BLX- $\alpha$, and mutation Gaussian probability methods are used.

Table 1: Set parameters in NSGA -II and SPEA-II

\begin{tabular}{|c|c|c|c|c|c|}
\hline $\begin{array}{c}\text { The size of } \\
\text { the archive }\end{array}$ & $\begin{array}{c}\text { The percentage } \\
\text { of the operation } \\
\text { of mutant }\end{array}$ & $\begin{array}{c}\text { The percentage of } \\
\text { the operation of } \\
\text { crossover }\end{array}$ & $\begin{array}{c}\text { The number of } \\
\text { implementation } \\
\text { procedures }\end{array}$ & Population & Algorithms \\
\hline
\end{tabular}




\begin{tabular}{|c|c|c|c|c|c|}
\hline- & 0.1 & 0.9 & 150 & 150 & NSGA -II \\
\hline 150 & 0.1 & 0.9 & 150 & 100 & SPEA - II \\
\hline
\end{tabular}

\section{Numerical reviewing of Not-dominated sorting algorithm based on Corner Sorting}

Table 2: Numerical problems without constraints

\begin{tabular}{|c|c|c|c|c|c|}
\hline $\begin{array}{l}\text { Pareto } \\
\text { space }\end{array}$ & $\begin{array}{l}\text { Optimal } \\
\text { solutions }\end{array}$ & The objective function & $\begin{array}{c}\text { Range of } \\
\text { design }\end{array}$ & $\begin{array}{c}\text { Number of } \\
\text { Variables }\end{array}$ & $\begin{array}{c}\text { Proble } \\
\text { m }\end{array}$ \\
\hline Convex & $x \in[0,2]$ & $\begin{array}{c}f_{1}(x)=x^{2} \\
f_{2}(x)=(x-2)^{2}\end{array}$ & {$[-10,10]$} & 1 & $\mathrm{SCH}$ \\
\hline Non-convex & $\begin{array}{c}x_{1}=x_{2}=x_{3} \\
\in[1 / v 3,1 / v 3]\end{array}$ & $\begin{array}{l}\mathrm{f}_{1}(\mathrm{x})=1-\exp \left(-\sum_{\mathrm{i}=1}^{3}\left(\mathrm{x}_{\mathrm{i}}-\frac{1}{\sqrt{3}}\right)^{2}\right) \\
\mathrm{f}_{2}(\mathrm{x})=1-\exp \left(-\sum_{\mathrm{i}=1}^{3}\left(\mathrm{x}_{\mathrm{i}}+\frac{1}{\sqrt{3}}\right)^{2}\right)\end{array}$ & {$[-4,4]$} & 3 & FON \\
\hline Non-convex & Reference[4] & $\begin{array}{c}\mathrm{f}_{1}(\mathrm{x})=\sum_{\mathrm{i}=1}^{\mathrm{n}-1}\left(-10 \exp \left(-0.2 \sqrt{\mathrm{x}_{\mathrm{i}}^{2}+\mathrm{x}_{\mathrm{i}+1}^{2}}\right)\right) \\
\mathrm{f}_{2}(\mathrm{x})=\sum_{\mathrm{i}=1}^{\mathrm{n}-1}\left(\left|\mathrm{x}_{\mathrm{i}}\right|^{8}+5 \sin \mathrm{x}_{\mathrm{i}}^{3}\right)\end{array}$ & {$[-5,5]$} & 3 & KUR \\
\hline Convex & $\begin{array}{c}X_{1} \in[0,1] \\
\quad X_{i}=0 \\
i=2, \ldots, n\end{array}$ & $\begin{array}{c}\mathrm{f}_{1}(\mathrm{x})=\mathrm{x}_{1} \\
\mathrm{f}_{2}(\mathrm{x})=\mathrm{g}(\mathrm{x})\left[1-\sqrt{\mathrm{x}_{1} / \mathrm{g}(\mathrm{x})}\right. \\
\mathrm{g}(\mathrm{x})=1+9\left(\sum_{\mathrm{i}=2}^{\mathrm{n}} \mathrm{x}_{\mathrm{i}}\right) /(\mathrm{n}-1)\end{array}$ & {$[0,1]$} & 30 & ZDT1 \\
\hline
\end{tabular}

Table 3: Numerical problems with constraints

\begin{tabular}{|c|c|c|c|c|}
\hline Constrain & The objective function & Range variable & $\begin{array}{c}\text { Number of } \\
\text { variables }\end{array}$ & Problem \\
\hline $\begin{array}{l}\mathrm{g}_{1}(\mathrm{x}) \equiv 9 \mathrm{x}_{1}+\mathrm{x}_{2} \geq 6 \\
\mathrm{~g}_{2}(\mathrm{x}) \equiv 9 \mathrm{x}_{1}-\mathrm{x}_{2} \geq 1\end{array}$ & $\begin{array}{c}\mathrm{f}_{1}(\mathrm{x})=\mathrm{x}_{1} \\
\mathrm{f}_{2}(\mathrm{x})=\frac{1+\mathrm{x}_{2}}{\mathrm{x}_{1}}\end{array}$ & $\begin{array}{c}0.1 \leq x_{1} \leq 1 \\
0 \leq x_{2} \leq 5\end{array}$ & 2 & Constr \\
\hline $\begin{array}{l}\mathrm{g}_{1}(\mathrm{x}) \equiv \mathrm{x}_{1}{ }^{2}+\mathrm{x}_{2}{ }^{2} \leq 225 \\
\mathrm{~g}_{2}(\mathrm{x}) \equiv \mathrm{x}_{1}-3 \mathrm{x}_{2} \leq-10\end{array}$ & $\begin{array}{c}\mathrm{f}_{1}(\mathrm{x})=\left(\mathrm{x}_{1}-2\right)^{2}+\left(\mathrm{x}_{1}-1\right)^{2}+2 \\
\mathrm{f}_{2}(\mathrm{x})=\left(\mathrm{x}_{1}-1\right)^{2}+9 \mathrm{x}_{1}\end{array}$ & $\begin{array}{l}-20 \leq \mathrm{x}_{1} \leq 20 \\
-20 \leq \mathrm{x}_{2} \leq 20\end{array}$ & 2 & SRN \\
\hline
\end{tabular}

Table 4: Comparison of results in the accuracy and extent indicators

\begin{tabular}{|c|c|c|c|c|c|c|c|}
\hline $\begin{array}{c}\text { Accuracy and } \\
\text { expansion } \\
\text { indicators }\end{array}$ & SRN & Constr & ZDT1 & KUR & FON & $\mathrm{SCH}$ & Algorithm \\
\hline Time(seconds) & 225.17 & 203.83 & 180.82 & 137.58 & 165.72 & 208.44 & \multirow{5}{*}{$\begin{array}{c}\text { NSGA -II } \\
\text { The proposed }\end{array}$} \\
\hline Spacing & 0.297 & 0.5570 & 0.4432 & 0.3937 & 0.3191 & 0.3628 & \\
\hline MID & 150.16 & 3.9074 & 0.708 & 17.762 & 0.9164 & 2.404 & \\
\hline Diversity & 190.38 & 30.694 & 12.594 & 37.751 & 12.416 & 25.561 & \\
\hline NOS & 150 & 150 & 150 & 150 & 150 & 150 & \\
\hline Time(seconds) & 233.10 & 229.44 & 227.11 & 221.38 & 221.04 & 222.71 & \multirow{5}{*}{ SPEA- II } \\
\hline Spacing & 0.7333 & 0.9458 & 0.7401 & 0.6850 & 0.677 & 0.6653 & \\
\hline MID & 153.33 & 3.9010 & 0.6815 & 17.796 & 0.9197 & 2.419 & \\
\hline Diversity & 190.374 & 29.786 & 12.411 & 33.788 & 11.820 & 25.6296 & \\
\hline NOS & 150 & 150 & 150 & 150 & 150 & 150 & \\
\hline
\end{tabular}




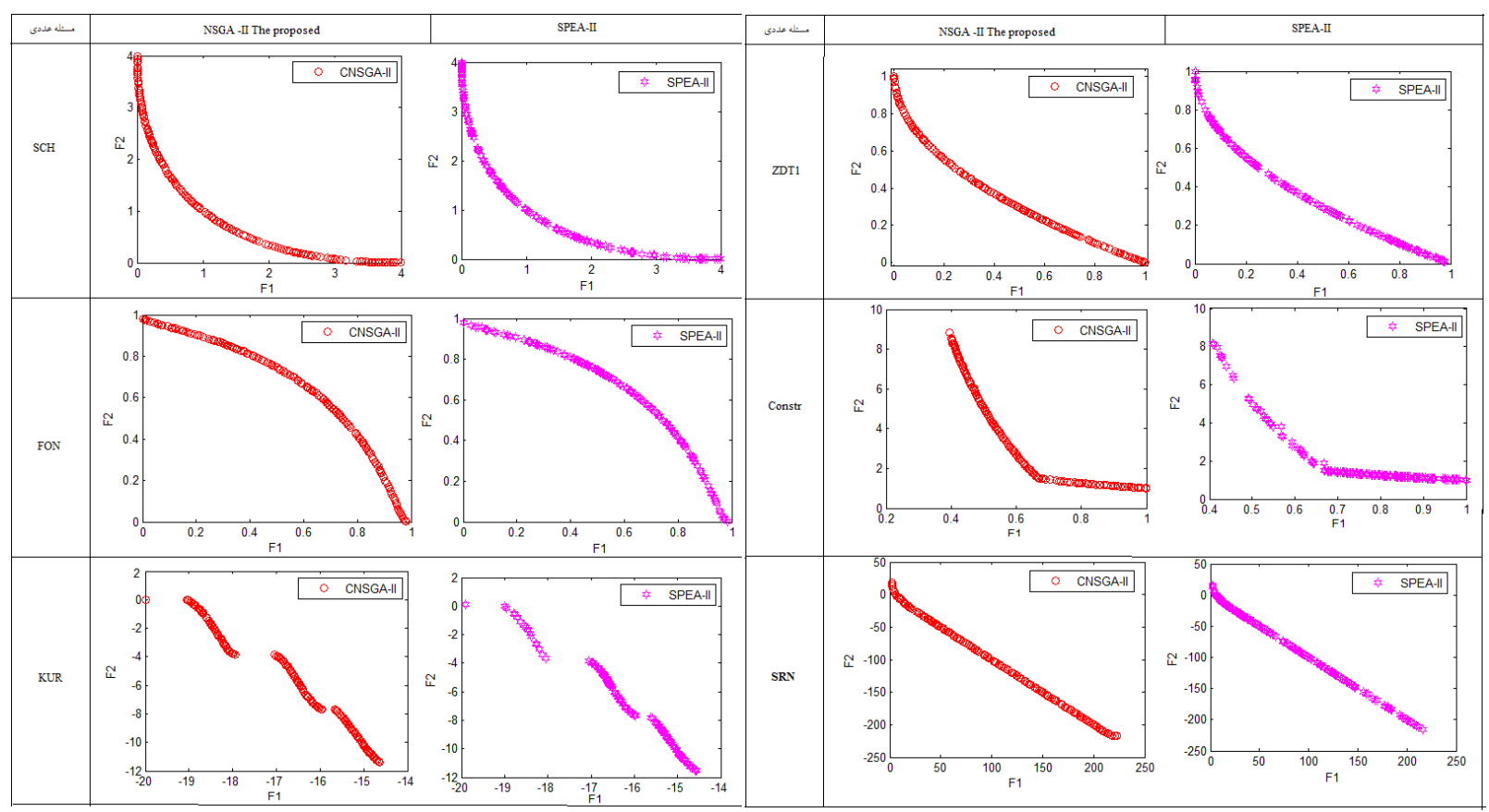

Figure 6-Showing Pareto curves in the numerical problems with constraints and without constraints

\section{Numerical Investigation of Truss}

\subsection{Three bars Truss}

Truss with 3 bars, here, in order to investigate checkout of the correctness of the output responses to the article Deb [40], to be compared .In this truss, the aim is to determine the minimum weight and the maximum diversion is in each node. To this end, using the proposed algorithm NSGA-II, the desired truss in terms of size and topology and configuration to be optimized simultaneously, in the form (6), the desired structure is visible. The allowed power of any member is equal to $5 \mathrm{KPa}$, and in the perpendicular members, it is $20 \mathrm{KPa}$, and the density and modulus of elasticity is $0.1 \mathrm{lb} / \mathrm{in}^{3}$ and $10^{7} \mathrm{pa}$. The transition zone between

$[-20,20] \mathrm{in}^{2}$, is Initialized. Here, a population of 50 , and the combined probability of 0.9 and mutation probability of 0.1 is used, and the method of single-point crossover and Gaussian mutation are used.

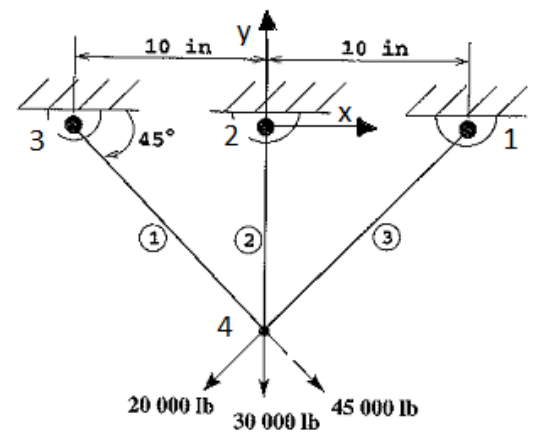

Figure 7- Three bars truss 


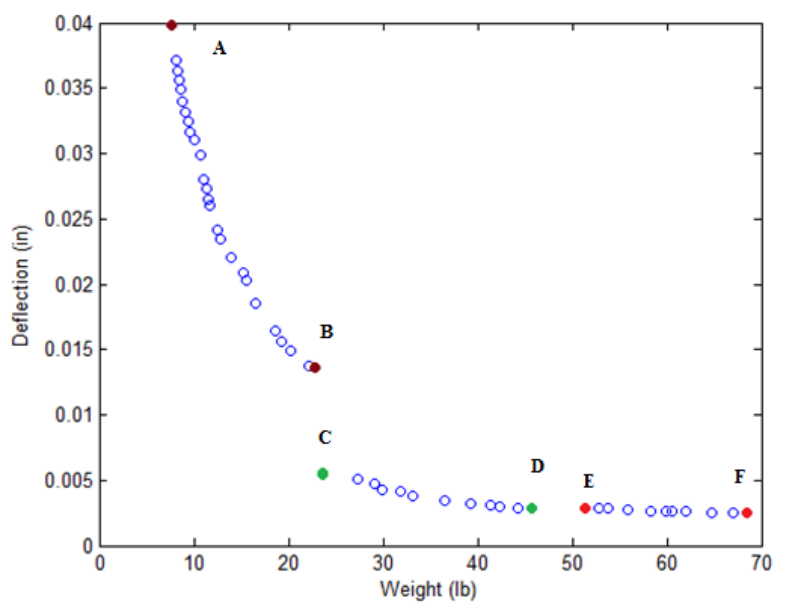

Figure 8- Not-dominated results obtained for three bars truss
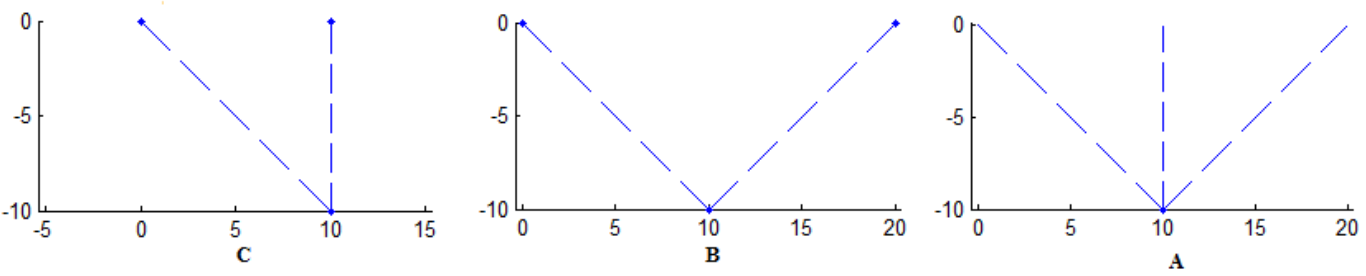

Figure 9- C: topology obtained for not-dominated solutions A to B three bars truss, B: topology obtained for notdominated solutions $C$ to $D$ three bars truss, $A$ : The topology obtained for not-dominated solutions $E$ to $F$, three bars truss

Table 5: A first and final solution. of different topologies of the three bar truss

\begin{tabular}{|c|c|c|c|c|c|}
\hline \multirow{2}{*}{ Solution } & \multicolumn{3}{|c|}{ Cross-sectional area (in ${ }^{2)}$} & \multirow{2}{*}{ Weight (lb) } & \multirow{2}{*}{ Deflection (in) } \\
\cline { 2 - 4 } & Left & Central & Right & & \\
\hline A & 2.0742 & 3.3154 & - & 7.6221 & 0.03793 \\
\hline B & 5.6377 & 10.5374 & - & 22.875 & 0.013633 \\
\hline C & 12.0324 & - & 6.5899 & 23.6063 & 0.0055669 \\
\hline D & 20 & - & 17.3883 & 45.6725 & 0.0029145 \\
\hline E & 20 & 20 & 14.9631 & 51.4453 & 0.0028966 \\
\hline F & 20 & 11.8308 & 20 & 68.3993 & 0.0025339 \\
\hline
\end{tabular}

Figure 8 shows the proposed algorithm is capable to find multiple solutions in a single run. Structure which has the lowest weight (solutions $A$ ) is equal to 7.6221 and the deviation of 0.03793 and a maximum weight (solutions F) is 68.3993 and deviation of 68.3993 and deviation of 0.0025329 and the corresponding topology in Figure 8 is shown. Not-dominated solution set shows valuable information about the bar truss design,. First, beyond all possible topologies, three topologies shown in Figure 3 in the Pareto optimal area, is found. Also any Pareto optimal solution, topologies are an appropriate towards the Pareto level, neighborhood solutions of any topology, in terms of the size are different in the transition regions. In the Table (5), six critical solutions in the figure are listed. It is clear that, for answers with minimum weight, solutions between $A$ and $B$ that truss only has left and right members, which are close to the optimal, diversity among the solutions because of diversity in transition areas occurs, and this issue for another three topologies is also true. Some important issues( $A$ to $F$ ), in the original study [40] is shown, for this purpose, $F$ minimum has minimum failure, 
because all members have reached to lowest according to the table (5) and the maximum allowable amount.

In the following, the results domain obtained in this study is approximately equal to their weight $[7.6221,68.3993] \mathrm{lb}$ and their failure rate is also approximately equal to[0.03793, 0.0025339$]$. The results obtained in the proposed algorithm show the suitable performance of this algorithm.

\subsection{The ten-bars truss}

The ten rod truss, with the same aim, determining the minimum weight and maximum deviation in each node is investigated. Which this purpose is achieved using the NSGA-II proposed algorithm, the desired truss in terms of topology and configuration and size at the same time is optimized, which in the figure (9) is visible. The allowed power any member is equal to the $25 \mathrm{KPa}$, Modulus of elasticity and density is $10^{7} \mathrm{pa}$ and $0.1 \mathrm{lb} / \mathrm{in}^{3}$, also the transition areas on the Interval $[-32,32]$ is initialized. Here, from a population of 100 , and the combined probability of 0.9 and mutation probability of 0.1 was used, and the method of single-point crossover and Gaussian mutation is used.

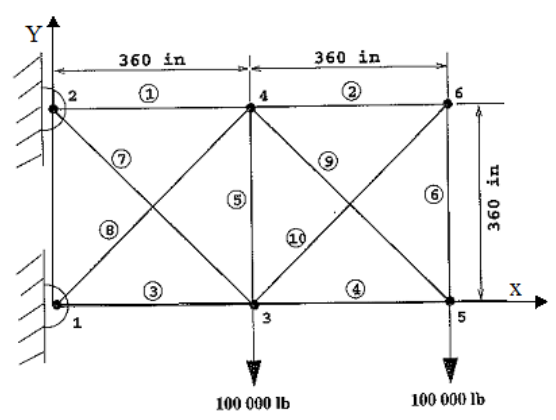

Figure10- ten-bar truss

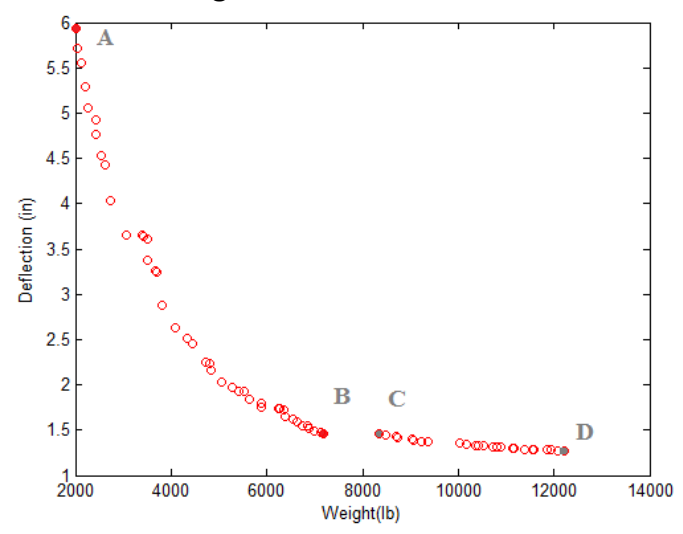

Fig 11-Not-dominated results obtained for the ten-bar truss
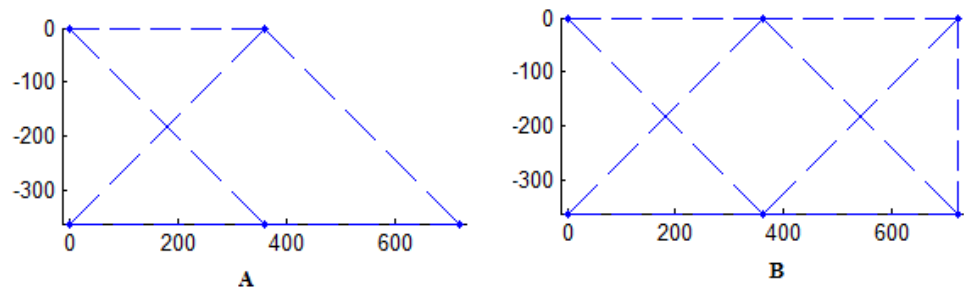

Figure 12- A: The topology obtained for not-dominated solutions A to B of the ten bars truss, B: C to D topology obtained for not-dominated solutions the three bars truss 
Table 5: Four first and final solutions of the different topologies of the three bars truss

\begin{tabular}{|c|c|c|c|c|c|c|c|c|c|c|c|c|}
\hline \multirow{3}{*}{ Answer } & \multicolumn{10}{|c|}{ Cross-sectional area (in ${ }^{2)}$} & \multirow{3}{*}{ Weight (lb) } & \multirow{3}{*}{ Deflection(in) } \\
\hline & \multicolumn{10}{|c|}{ Number Elements } & & \\
\hline & 1 & 2 & 3 & 4 & 5 & 6 & 7 & 8 & 9 & 10 & & \\
\hline$A$ & 10.8546 & - & 6.9968 & 10.0093 & - & - & 6.5264 & 6.7789 & 6.6336 & - & 2025.1245 & 5.9301 \\
\hline$B$ & 32 & - & 32 & 32 & - & - & 32 & 32 & 9.1981 & - & 7182.6386 & 1.4633 \\
\hline C & 32 & 2.2727 & $7 \mid 2.0830$ & 24.6277 & - & 31.4278 & 32 & 32 & 3.5729 & 31 & 8345.3159 & 1.4568 \\
\hline D & 32 & 32 & 32 & 32 & - & 32 & 32 & 32 & 32 & 31 & 12225.7844 & 1.2732 \\
\hline
\end{tabular}

Figure (11) shows the not-dominated results obtained. Interestingly, many possible topologies of the proposed algorithm have found only two specific topologies. Structures, with minimal weight lb2025.1245, and deviation 5.9301, by comparing the results of Deb et al [40], the algorithm has a good performance in parameters of the accuracy extent in not-dominated solutions, with research on critical results, Studies of the Deb et al., we can say that the obtained results are very close to the actual not-dominated solutions. It is clear that the proposed algorithm is able to find a number of solutions. What is evident is that, not-dominated results obtained in separate areas, are located in different topologies. In such areas, using different transition regions, while the same topology, they is changing. Each area has limited value for objective function. To find a solution beyond these limits, other topologies must be used.

\section{Conclusion}

It is better that the conclusion be divided into two parts. The first part numerical reviews the algorithm not-dominated sorting, based on Corner Sorting, the second part reviews three bars and ten bars truss in the not-dominated sorting algorithm based on Corner Sorting. In the first section, it was shown that algorithm in parameters of the accuracy and extent in presented parameters has better performance than SPEA-II. The results in the three bars truss show that, the proposed algorithm has the ability to find different topologies in the transition areas, which can result from the proper performance of this algorithm. However, on three bars truss proposed algorithm, by identification three types of topology, and obtaining the maximum deviation or failure equal to 0.03793, the lowest weight is 7.6221.So we can say that the algorithm introduced in the expansion and accuracy has good performance, as compared with the results of Deb [40], in which minimum weight of 7.6318 and the maximum deviation is .0 .038 then we can say that our results achieved have good performance. In the ten-bars truss, the results and interpretations in Chapter V, were mentioned, and the results show that the proposed algorithm has a high ability to find different topologies, and well, the algorithm has a high ability to find solutions very close to the Pareto optimal level or real not-dominated solutions, and also the truss has the least weight 2025.1245, and the maximum deviation 5.9301 .

\section{References}

[1] Coello, C. A. C. (1999). "A Comprehensive Survey of Evolutionary-Based Multiobjective Optimization Techniques". Knowledge and Information Systems1(3),269-308

[2] American Institute of Steel Construction (AISC). "Manual of steel constructionallowable stress design". 9th ed. Chicago: American Institute of Steel Construction; 1989. [3] CoelloCAC, Lechuga MS. "MOPSO: a proposal for multiple objective particle swarm optimization". In: Proceeding congress on evolutionary computation (CEC'2002), vol. 1; 2002. p. 1051-6.

[4] Coello CAC, Van Veldhuizen DA, Lamont GB. " Evolutionary algorithms for solving multi-objective problems". New York, USA: Kluwer Academic Publishers;2002. 
[5] Coello CAC, Pulido GT, Lechuga MS. "Handling multiple objectives with particle swarm optimization". IEEE Trans Evolution Comput 2004;8:256-79.

[6] Deb K, Pratap A, Agarwal S, Meyarivan T. "A fast and elitist multiobjective genetic algorithm: NSGA-II". IEEE Trans Evolution Comput2002;6:182-97.

[7] Deb K. "Multi-objective optimization using evolutionary algorithms. " Wiley, UK: Chichester; 2001.

[8] Deb, K. "Evolutionary Algorithms for Multi-Criterion Optimization in Engineering Design". Proceedings of Evolutionary Algorithms in Engineering and Computer Science , Vol. 62,No . 99,pp. 135161,(1999)

[9] Vanderplaats, G.N. \& Moses F., "Automated Desing of Trusser for optimum Geometry", joural of the structural division, ASCE, Vol 98, No. ST3, pp. 671-690(1972).

[10] Gero MBP, Garc AB, Diaz JJDC. " Design optimization of 3D steel structures: genetic algorithms vs. classical techniques". J Construct Steel Res2006;62:1303-9. [11] Goh CK, Ong YS, Tan KC. "An investigation on evolutionary gradient search for multiobjective optimization". In: IEEE world congress on, computational intelligence; 2008. p. 3741-6.

[12] Gou X, Cheng G, Yamazaki K." A new approach for the solution of singular optima in truss topology optimization with stress and local buckling constraints". Struct Multidisc Optim. 2001;22:364-72.

[13] Haritigan JA. "Clustering algorithms". John Wiley and Sons; 1975.

[14] Jan MA, Zhang Q. "MOEA/D for constrained multi-objective optimization: some preliminary experimental results". Comput Intell (UKCI) 2010;1-6.

[15] Kaveh A, Rahami H. "Nonlinear analysis and optimal design of structures via force method and genetic algorithm". Comput Struct 2006;84:770-8.

[16] Kaveh A, Talatahari S. "Optimal design of skeletal structures via the charged system search algorithm". Struct Multidisc Optim 2009;37:893-911.

[17] Kaveh A, Talatahari S. "A novel heuristic optimization method": charged system search. Acta Mech 2010;213:267-89.

[18] Kaveh A, Talatahari S. "Charged system search for optimum grillage systems design using the LRFD-AISC code". J Construct Steel Res2010;66:767-71. [19] Lee KS, Geem ZW. "A new structural optimization method based on the harmony search algorithm". Comput Struct 2004;82:781-98.

[20] Deb,K. \& Gula ,S., "Desugn of Truss Structure for Minimum Weight Using Genetic Algorithms", Finite Elements in Analysis and Design, Vol. 37, PP. 447-465, (2001).

[21] Li H, Zhang Q. "Multi-objective optimization problems with complicated Pareto sets". IEEE Trans Evolution Comput 2009;13:284-302.

[22] Liu M, Burns SA, Wen YK. "Multi-objective optimization for performance-based seismic design of steel moment frame structures". Earthq Eng Struct Dynam2005;34:289306.

[23] Mathakari S, Gardoni P, Agarwal P, Raich A. "Reliability-based optimal design of electrical transmission towers using multi-objective genetic algorithms. " Comput Aided Civil Infrastruct Eng 2007;22:282-92.

[24] Mostaghim S, Teich J. "Strategies for finding good local guides in multiobjective particle swarm optimization (MOPSO). " In: Proceedings of the IEEE swarm intelligence, symposium; 2003. p. 26-33.

[25] Mostaghim S, Teich J. "Covering pareto-optimal fronts by subswarms in multiobjective particle swarm optimization. " In: Congress on evolutionary computation (CEC'2004), vol. 2; 2004. p. 1404-11.

[26] Ohsaki M, Kinoshita T, Pan P. "Multi-objective heuristic approaches to seismic design of steel frames with standard sections." Earthq Eng Struct Dynam2007;36:1481-95. 
[27] Imai, K. and Schmit, L.A. (1981), "Configuration optimization of trusses", ASCE J. Struct. Div. $107,745-756$.

[28] Paya I, Yepes V, Vidosa FG, Hospitaler A. "Multi-objective optimization of concrete frames by simulated annealing".Comput Aided Civil Infrastruct Eng2008;23:596-610.

[29] Salomon R. "Evolutionary algorithms and gradient search: similarities and differences". IEEE Trans Evol Comput 1998;2:45-55.

[30] Sierra MR, Coello CAC. "Improving PSO-based multi-objective optimization using crowding, mutation and $\varepsilon$-dominance". In: Proceeding of evolutionary multi-criterion optimization conference. Guanajuato, Mexico; 2005. p. 505-19.

[31] Sindhya K, Sinha A, Deb K, Miettinen K. "Local search based evolutionary multiobjective optimization algorithm for constrained and unconstrained problems". In: CEC'09 proceeding of the eleventh congress on evolutionary computation; 2009.

[32] Su RY, Wang X, Gui L, Fan Z. "Multi-objective topology and sizing optimization of truss structures based on adaptive multi-island search strategy". Struct Multidisc Optim 2010;43:275-86.

[33] Toscano PG, Coello CAC. "Using clustering techniques to improve the performance of a particle swarm optimizer. " In: Proceeding of genetic evolutionary computation conference. Seattle, WA; 2004. p. 225-37.

[34] Mlenjenk,H.p. \& Jehle,U. \& Schirrmacher, "Second-Order Approximations in Structural Genesis and Shape Finding", international journal for numerical methods in engineering, Vol. 33, pp. 853-872.(1992)

[35] Goldberg, D. E. and Samtani, M. P. (1986). "Engineering optimization via genetic algorithm". Ninth Conference on Electronic Computation, 471- 482.

[36] Zhang Q, Li H. MOEA/D: "a multi-objective evolutionary algorithm based on decomposition". IEEE Trans Evolution Comput 2007;11(6):712-31.

[37] Zitzler E, Laumanns M, Thiele L. "SPEA2: improving the strength Pareto evolutionary algorithm". Zurich, Switzerland: Swiss Federal Institute Technology; 2001.

[38] Zitzler E, Deb K, Thiele L. "Comparison of multi-objective evolutionary algorithms": empirical results. Evolution Comput 2000;8(2):173-95.

[39]Wang, H and Yao. X., "Corner Sort for Pareto-based Many-Objective Optimization". IEEE Trans

Cybern. (2013).

[40] Deb, K., Khan, N. and Jindal, S. "Optimal truss-structure design for multiple objectives". Tenth National Seminar on Aerospace Structures, pp. 168-180.(2000)

[41] Vanderplaats, G.N. \& Moses F., "Automated Desing of Trusser for optimum Geometry", joural of the structural division, ASCE, Vol 98, No. ST3, pp. 671-690(1972).

[42] Vanderplaats, Garrant,N. \& Moses,Fred, "Automated Desing of Trusser for optimum Goemetry", Structural Division, Vol. 98, No. ST3, (1972)

[43] Wang.S.Y. \& Sun.y. Gallagher,R.H., "Sensitivity Analysis in Shape Optimization of Continuum Structurws", Comuters \& Sturctures, Vol. 20, No. 5, pp. 855-867, (1985).

[44] Wu, S.j \& Chow,P.T., "Integrated Discete and Configuration optimization of trusser using Genetic Algorithms", Computer \& Sturcture, Vol. 55, No.4, PP. 695-702(1995).

[45] Yeniay, Ozgur., "Penalty Function Methods for Consturained Optimiazation with Genetic Algorithms", Mathema cal and computa onal Applica ons. Vol. 10, No. 1, pp 45-56. (2005). 